\title{
Life Stories and Biography: A Means of Connecting Family and Staff to People with Dementia
}

\section{Authors \& Organisations:}

Dr Ursula Kellett RN BA(Hons) MN PhD

Senior Lecturer, Research Centre for Clinical and Community Practice Innovation, Griffith Institute of Health \& Medical Research, Griffith University

School of Nursing \& Midwifery, Kessels Rd., Nathan, QLD, 4111, Australia

t: +617 37355227 | f: +617 37357984 | e: u.kellett@griffith.edu.au

Professor Wendy Moyle RN BN MHSc PhD

Deputy Director, Research Centre for Clinical and Community Practice Innovation, Griffith Institute of Health \& Medical Research, Griffith University, Australia

Dr Margaret McAllister RN MHN EdD

Associate Professor, School of Nursing and Sport Sciences

University of Sunshine Coast, Australia

Christopher King RN BHSc(Nursing) DipBus

Group Manager, Residential Services, Spiritus, Brisbane, Australia

Fran Gallagher RN BEd (Nursing) MA

Research Assistant, Research Centre for Clinical and Community Practice Innovation, Griffith Institute of Health \& Medical Research, Griffith University, Australia

\section{Source of support:}

Acknowledgements are extended to Griffith University and the industry partner Spiritus, Brisbane, Australia for awarding this project a Griffith University Industry Collaborative Grant. 


\section{ABSTRACT}

\section{Aims:}

This article assesses the Family Biography Workshop (FBW) designed to support family and staff to co-construct the history of the person with dementia in residential care.

\section{Background:}

Family-staff conflict in residential dementia care is a major stressor that disturbs effective relationships and contributes to stress. Biographical research has been found to improve communication and promote family-staff relations. Few studies focus on family biography as an approach that promotes positive relations that translate into inclusive care interactions.

\section{Design:}

A qualitative descriptive approach was used to assess the influence of participation in the FBW and the impact of developing biographical knowledge on family-staff care-giver attitudes, perceptions of roles, conflict and the subsequent management of stress using participatory care practices.

\section{Methods:}

The FBW process involved seven family care-givers, seven staff and one researcher working collaboratively through a series of 6 weekly two-hour sessions, designed to help them build a biography of the person with dementia.

\section{Results:}

For family care-givers, reviving memories of their relatives as 'whole' persons enabled some to 'stand outside' and see beyond the disease-saturated context. For staff, 'opening possibilities' of 'seeing' the resident within the family context empowered them to engage in genuine participatory practices. Residents benefited from being connected as staffs' 'know how' in initiating and engaging developed.

\section{Conclusion:}

Future research will examine the effects of the FBW on the dynamics of family-staff roles and relationships. This research aims to reduce stress from role inadequacy, task burden, poor relationships and improve staff attitudes towards family participation.

\section{Relevance to Clinical Practice:}

This study substantiated the FBW by: revealing understanding of the meaning of biography work for family and relatives in care; providing effective support that empowers staff to confidently relate; and fostering engagement in inclusive care practices that encourage residents' initiatives. 
Key words: Life story, biography, staff-family relations, dementia, long-term care, relationshipcentred care 


\section{INTRODUCTION}

Family-staff conflict in residential care has been identified as a major stressor that disturbs the development of effective therapeutic relationships (Haesler et al. 2006, 2007). It is well documented in the international literature that residential staff are highly stressed (Brodaty et al. 2003, Gaugler et al. 2004, McGilton \& Hall 2007). In Australia, a recent survey found that 50 per cent of aged care nurses reported extremely high stress levels (Hegney et al. 2005). Moyle et al. (2003) found that tension with role expectation among residential care staff was a key factor contributing to work-related stress and job dissatisfaction. For Bern-Klug and Horbes-Thompson (2008) in North America, workplace tension was particularly problematic when role expectations differed, leading to strained relations.

But care-giver stress is not isolated to staff alone. Family stress related to the admission of a relative into residential care is widely reported in international studies (Kellett 1999 a b, Cheek \& Ballantyne 2001, Gaugler et al. 2001, Wilkes et al. 2008). Role change has been identified as a significant challenge families face when adapting to their new care-giving context (Hertzberg \& Ekman 2000, Sandberg et al. 2002). Poor role definition for families leads to confusion in terms of care participation (Kellett, 2000, Ryan \& Scullion 2000) and creates barriers to participatory dementia care (Bauer 2006).

Research suggests that problems emerge when there is a mismatch between the structure of the organisation, roles and tasks it assumes from families (Pillemer et al. 2003). The potential for stress as a result of family-staff conflict is heightened because facilities represent the classic case of a formal institution seeking to take over primary care tasks and to 'fit' the performance of tasks into a bureaucratic, routinised framework. Stress for families has been described in terms of losing control (Kellett 2007), feeling a need to oversee and advocate, feeling undervalued and being treated like a visitor or a client and experiencing less intimacy (Haesler et al. 2006, 2007).

This article describes a pilot study that was undertaken in 2007-2008 as an industry partnership project between Griffith University, Research Centre for Clinical and Community Practice Innovation and Spiritus, Brisbane, Australia. The study built on existing international research (Hepburn et al. 1997, Maas et al. 2004) by trialling the implementation of a participatory approach to dementia care facilitated through a Family Biography Workshop (FBW). The FBW was designed to provide a defined role for family care-givers of people with dementia in care to assist staff in personalising nursing care. The FBW provided a structured process that facilitated 
engagement of staff, family members and friends of the person with dementia in the coconstruction of biographies of the lives of the person with dementia in residential care. The purpose of the FBW process was to: ensure that the views of family and people with dementia were heard; understand the person with dementia in the context of his or her family and intergenerational history; and promote sensitive and relationship-centred care informed and shaped by knowledge of personal identity and meaning in life.

\section{BACKGROUND}

Recent North American research that aims to improve family-staff relationships in long-term aged care (Jablonski et al. 2005, Maas et al. 2004) indicates that what facilitates positive relations in nursing homes remains unclear (Gaugler \& Ewen 2005). This body of research clearly illuminates the complexity of important relationships among families, residents and staff in the organisational context of long-term aged care. It recognises that successful nursing care is predicated on a better understanding of the dynamics of this relationship (Kellett 2007). One way of achieving this is through the use of biographical approaches that shape and inform inclusive care.

Although an immature field of research (McKeown et al. 2006), the use of life story and family biographical approaches in aged care have assisted us to learn how best to deliver sensitive and effective support that empowers staff to confidently relate to family and residents and engage in flexible, inclusive care practices informed by life story (Clarke et al. 2003, Keady \& Williams 2007). The value of biographical approaches have been categorised according to their purpose: understanding the person (Bateson et al. 2002), looking beyond the diagnosis and better explaining presenting behaviours (Clarke et al. 2003); and improving communication and relationships between care staff, resident and family (Hansebo \& Kihlgren 2000). More broadly, Moos and Bjorn (2006) argue that life story studies generally fall into three categories: those that raise self-esteem and self-integration; those that improve quality of life and those that change behaviour.

McKeown et al. (2006) critique the body of biographical research stating that studies exploring meaning of life story work focus on the experiences of staff but what remains limited is our understanding of the meaning of biography work for family and relatives in care. Moos and Bjorn (2006) add their criticism of a dearth of studies that feature interventions that enhance a sense 
of identity through the sharing of the individual's life story, that translate the life story into care interactions and that actively encourage residents' initiatives.

\section{AIMS}

A description of the FBW process is provided in this article. This article also presents a descriptive qualitative assessment of the FBW. This assessment focuses on the impact of newfound biography knowledge on family-staff care-giver attitudes, perceptions of roles, conflict and the subsequent management of stress using participatory dementia care practices. Such an assessment is deemed important in gaining a better understanding of how the FBW can be used to reduce stress from role confusion and poor relationships and provide guidance on how to manage conflict in a supported and inclusive care environment.

\section{METHODS}

\section{Family Biography Workshop}

The FBW design was tailored to the intended purpose of the study. Working together provided staff and family caregivers with the opportunity to spend focused time on sharing 'local knowledge' (Harvath et al. 1994) about their relative in his or her family and intergenerational context, complete with personal characteristics, life accomplishments and the meaning attributed to events and achievements throughout life.

The FBW process, a series of 6 weekly two-hour sessions, involved families and staff completing a set of exercises designed to help them build a biography of the life of the person with dementia. Staff and family carers were partnered according to their involvement with one another in the care areas of the facility. Family care-givers in between workshop sessions would relay the content of shared conversations and show their relatives the developing biography. Staff too reported how they had opportunities to positively use developing biography knowledge in their care for residents of participating family care-givers. Thus incrementally, sharing biographical materials with the resident, both family members and staff involved the person with dementia in the study process.

\section{Participants}

The FBW involved seven family carers (two adult children, five spouse) and their relatives in care (one mother, one father, five husbands), seven care staff (two nurses, five therapists) and one researcher. Purposeful sampling techniques were employed to ensure access to those 
family members and staff who were engaged in the every day care of the person with dementia in the long-term care setting.

The following inclusion criteria were used in selecting prospective participants:

1. family care-givers who knew and were willing to share the life history of their relative who had a diagnosis of dementia or met the DSM-IV criteria;

2. family care-givers who had direct experience of providing care for their relative within the residential care context; and

3. care staff (all levels of nurses, care workers and therapists) involved in providing direct care and/or planning of care for residents with dementia.

\section{Ethical Issues}

Formal procedures were followed to gain ethical clearance from the executive boards of the participating aged care service provider and the relevant university human research ethics committee. Direct access to participants ensured the voluntary nature of involvement. The project was advertised in the following ways: fliers placed on facility noticeboards; an advertisement in the facility's newsletter; and through an information session to which interested family and staff were invited. This session allowed for discussion relating to the study's purpose, research process and potential risks and benefits of involvement. At this session interested participants signed informed consent forms indicating their willingness to be involved in the study.

\section{Focus Groups}

Following the completion of the FBW two focus groups were conducted in 2008 with all the participants who had been involved in the workshop sessions. Both focus groups were audiorecorded with permission, lasting one to one and a half hours. The first group which took place 1 week following the FBW focused on eliciting information about the family care-giver and staff experience of being involved in the FBW. The focus group questions were divided into two parts. The first part focused the group on questions related to the workshop process, for example, 'Do you think it is important to know about the family history of your relative/resident?' 'Why?' 'What aspects of the workshop assisted you to complete the family biography?' 'What aspects of the workshop did not assist you?' The second part focused the group on questions related to building communication, developing relationships and partnerships, for example, 'How has the workshop assisted you in sharing/co-constructing the family history of your relative/resident?' 
'How has the workshop assisted you to build a foundation for sharing the care-giving for your relative/resident?' 'How do you believe this shared involvement will support better care for your relative/resident?'

The second focus group took place five weeks after the final FBW session allowing staff and family time to return to their day to day situation in providing care for the person with dementia. The second group focused on the influence of participation in the FBW on knowledge, attitudes, perception of roles, relationships and care involvement and practices in the organisational context of long-term dementia care.

Four areas of questioning directed the second focus group process. The first group of questions focused on the impact of FBW on family-staff interactions, relationships and care (family-staff) relationship, for example, 'Can you tell me whether you have noticed any change in the interactions you have with each other as family and staff members following the FBW?' 'What impact has any change had upon your relationship with each other (family carer and staff)?'. The second group of questions focused on the impact of FBW on family-staff-resident interactions, relationships and care, for example, 'Can you tell me whether you have noticed any change in the interactions you have with your family member/resident following the family biography workshop?' 'What impact has this (answer to q1) had upon your relationship with your relative's/resident's?'. The third group of questions focused on the impact of FBW on care roles, for example, 'What impact has any relationship change had upon your role as a carer (family and staff)?' 'Can you provide examples of role change?'. The final group of questions focused on the impact of FBW on care practices, for example, 'Has biography knowledge influenced the planning, provision and experience of dementia care for your relative/resident/family carer/staff member?' 'How?'.

\section{Data Analysis}

All audio tapes were transcribed verbatim and together with the researcher's field notes comprised the data set for analysis. Two researchers independently analysed the two focus group transcripts using Luborsky's (1994) technique for thematic analysis, a method of content analysis especially appropriate for the analysis of qualitative interview data obtained from semistructured focus groups and interviews. In this study themes consisted of statements concerning the experience of FBW and its impact on communication, roles, relationships and care practices. The process of data interpretation involved independent then consensual interpretations of all 
aspects of the text. After each researcher read and identified themes and major topics, the team met to discuss interpretation in an effort to understand the text. Any conflicting interpretations were reviewed by careful re-reading for evidence of interpretation matched by sections of text.

\section{RESULTS}

A range of results are structured in this article in relation to the experience of the FBW for family, staff, people with dementia and the organisational benefits and challenges of integrating a biographical approach into residential dementia care.

\section{Family - standing outside}

'Standing outside' emerged as a theme with four characteristics: freeing the family from the present; breaking free of the disease-saturated narrative, gaining insight into grieving and healing and learning something about my relative not previously appreciated.

The experience of recalling important events and times across the relative's lifespan enabled the family care-givers to turn their thoughts and attention to their relative as a person who had lived, developed characteristics, enjoyed achievements and attributed meaning to events across a lifetime. Provided with the supported opportunity to recall their relatives whole life story family care-givers were enabled to distance themselves from their focus on immediate dementia related care-giving. Reviving memories of their relatives as 'whole' persons enabled some of the family care-givers to 'step out' of their everyday experience and see beyond the diseasesaturated context:

I think it's made me, having to bring out the story of the life, it seems to have allowed me to let go of something that I was holding back, 'stand outside' and see the bigger picture.

Revival of these memories provided renewed strength for family care-givers as they regained a rich sense of meaning and accomplishments of their relatives' lives. This strength enabled them to cope with the impact of the dementing illness in a more positive way. For some, a personal benefit was realised as they gained insight into their experience of the grieving process:

It is an emotional thing looking at the old photos and remembering things. That's because we are in a process of grieving. But I am learning to look at photos that can 
make me feel sad and realise the joy of having had that time and those memories rather than never having had them.

Others having revisited memories of family life past began to look at their relatives in different ways:

I think about my memoires in a different way having looked back through all these things again. I sort of see things in Dad that had never struck me before.

\section{Staff - opening possibilities}

'Opening possibilities' emerged as a theme with four characteristics: having a point of reference to communicate with resident and family, appreciating the resident and family member as people bound by a familial history, developing insight and understanding into behaviour and developing confidence to relate as a person.

For staff, knowledge of the life story opened up purposeful opportunities to connect with residents and reminisce about events in their lives to which they had attributed significance and importance:

Some staff don't know how to start a conversation (pause) particularly with people in the dementia ward. They find it very difficult and I think having to read the biography helps them to approach that person and start a conversation using stories in the history. It's a way into their minds.

Knowledge of the biography also assisted staff to manage difficult care situations:

If a challenging behaviour comes up that we don't understand now we can think about it in the light of the person's history. So it becomes an expression of need rather than a difficult behaviour and the history helps you to connect and manage the situation more effectively.

Such knowledge and possibilities for human connection further enhanced the care staffs' appreciation and respect of the person with dementia as a person embedded in a family and intergenerational context: 
I have noticed a huge difference in how I think having been in this group. When I approach a resident I start to think: who is this person? what interests might they have? what are they like as a person?. It gives you a more human focus.

The more insight staff gained in identifying aspects of family life and 'seeing' the person with dementia in the family context, the more empowered they felt to provide relationship-centred care rather than task-oriented care. Staff described their changed perception in terms of being able to appreciate how the resident was a husband or a father etc:

It was nice to put them together as a couple even though we know that they are married it's still the wife goes back home and the husband is here. When you learn about their story and read the different things they have enjoyed and put it together, you can see them as close together as a couple (pause) it's brought them together like a family, so that we can relate to Colin in a different way.

'Seeing' the person with dementia in family context enabled staff to develop confidence in their ability to relate on a personal level and develop a more meaningful relationship:

I am more conscious now when I go into someone to try to find something that is relevant and important to them.

Participating staff also commented on a change of attitude that influenced how they approached both resident and family care-givers. Their developing insight into the experience of family caregivers enabled staff to embrace inclusive care practices:

I've found that it gives me a different way of looking at the person ... I have I feel more respect for them instead of seeing them as a person with dementia I see them as a person first and the dementia is just (pause) an unfortunate sideline.

I think I have gained a more caring focus and a much greater understanding of the family caregivers and what they are going through. 
Staff commented on how the FBW experience had enabled them to feel as though they were a part of the family of the person with dementia. The participatory approach to developing the life story of the person with dementia was described as a platform for developing a partnership and sharing knowledge of the resident from different perspectives:

And just seeing how much you all care about your family member has been great (you know) that makes us feel like we are a part of that as well, that we did really care and that we're together.

\section{Person with Dementia - knowing how}

'Knowing how' emerged as a theme with two characteristics shared by both staff and family: knowing how to stimulate and provoke memories and knowing how to calm the person with dementia using biography.

People with dementia benefited from being more socially stimulated as staffs' confidence to initiate and engage using knowledge of family biography developed. This exchange provided increasing opportunities to see the person with dementia as a person within their family context, thus improving the quality of ongoing interactions. Family care-givers experienced great comfort from observing staff purposefully using knowledge of their relatives lives to shape and guide their interactions and care-giving:

He has always been so interested in building and making things... (lists building achievements)... It might just be a point of giving him something in his hands that makes him feel safe. So this knowledge I think is very important ...I think it's calming him.

Thus a benefit of using family biographical knowledge was discussed in terms of knowing how to calm and settle the person with dementia. As behaviour became more readily understood by staff, family care-givers experienced a sense of confidence in staff members' ability to manage changes in their relatives' condition:

You can talk about things you know where important in the person's life. So when she is upset or wandering you can talk about past history, what she has have done, what she can remember and it settles her down. 
Residents were perceived by staff and family to respond as if they were known to them as friends, family and not strangers ignorant of them as people:

They are not strangers because they know something about you. My husband is surprised when you say something to him about his life. It makes him feel important that someone knows something about him and they can talk about it.

\section{Organisational Issues - complementing the organisation}

'Complementing the organisation' emerged as a theme with three characteristics: promoting community, the challenges of integrating FBW in practice and the complexities of division of labour and responsibility.

Staff members who were not participants in the project, but who subsequently became interested in the biographies, were observed sitting, talking and sharing stories with residents:

I've seen a couple of staff outside this group look at the biography, sit down and start chatting about the past history. Even in their own time and they have had a good conversation.

The benefit of co-creating a family biography for each person with dementia was recognised in terms of fostering a sense of community and feelings of belonging for the family and staff alike. This benefit was very much acknowledged by all participants as being vital, especially at the time of admission into a residential facility and in developing care plans for the person with dementia in the early days post admission.

However, organisational challenges to integrating the FBW in its current form were identified. Staff participants stated that some families are not ready to develop biographies until they come to terms with the considerable changes in the lives of the person with dementia and subsequently to family. It was acknowledged that some families are unable to come to terms with their family situation:

Some families are frightened, they feel their business is their own business and they haven't come to terms yet with their changing situation. 
Moreover, admission time is associated with multiple form filling and collection of information. With this focus participating family care-givers described their feelings of confusion and being lost, unsure of what information was deemed important and relevant at that time. Following on from the immediate admission phase, ongoing assessment and care planning involved several disciplines, each discipline requiring different types of information to input into the plan of care and often excluding family care-givers:

I found admission time very difficult with all the papers and the lass is asking all these questions and there are like 25 forms to fill in. Your mind is not functioning anyway and it is really hard to focus at this time. Thinking about life stories is too difficult at this time as you are in survival mode.

The care plan is written within the first month following the resident's admission. So unless they have that information (biography) when they first come in then it doesn't happen.

Given these challenges several recommendations for future studies were discussed. In particular, the need for a longitudinal design, commencing the process of developing the family biography in the community, at-home, so that information is available should admission to a residential setting eventuate; using life stories as an education strategy for orienting existing and new staff; linking new families with a staff member responsible for facilitating the incremental collection of biography information; linking existing and new families using established support networks; and modifying case conference approaches to involve family members, providing a platform for ongoing sharing of life story information.

\section{DISCUSSION}

Family care-givers in this study clearly identified an increased sense of satisfaction through being empowered to contribute family knowledge that was shared with, recognised and valued by participating staff. Previous studies have communicated an improved sense of belonging (Kellett 2007), a healthy sense of well-being and competence, a reduction in feelings of anxiety and depression (Sebern \& Whitlatch 2007) and an improved quality of life for family care-givers fuelled by the knowledge that their contribution has enhanced possibilities for their relative to receive the best possible care (Kellett 2007). 
In common with Hepburn et al. (1997) this study found that reviving memories of the 'whole' person with dementia enabled some of the family care-givers to 'step out' of their every day experience and see beyond the disease-saturated context. This notion of 'stepping out' and 'standing outside' has been documented in other studies of family care-givers experiences of dementia care in residential settings (Kellett 2007). Furthermore, the FBW provided family carers with an opportunity to experience themselves as a group rather than disconnected individuals. Clarke et al. (2003) in their biographical research in hospital care confirm that family care-givers experience a therapeutic benefit from sharing support throughout the process of biography construction and beyond with others.

This study clearly identified the benefits for residents who were socially stimulated by staff and family care-givers using their knowledge of them as people in their intergenerational context. This knowledge of family biography influenced both the initiation and the process of every day dementia care practices. Previous studies have found that benefits for residents are realised in terms of a reduction in the sense of separation (Sandberg et al. 2002), a reduction in feelings of loss (Maas 2004), an increase in reports of feeling 'close' with staff (Gaugler \& Ewen 2005) and a reduction in physio-chemical interventions for behaviour management (Jablonski et al. 2005).

These benefits motivated all participants in this study to interact in less superficial and remote ways, improving relationships and promoting partnerships. Hertzberg et al. (2001) have argued that for staff engaged relationships are vital in positively anticipating inclusive care as an integral part of prescribed work rather than an unwanted imposition. In this study engaged interaction that fostered inclusive care was facilitated in two ways. First, as staff began to appreciate the person with dementia within his or her family and intergenerational context, the more empowered they felt to provide more individualised and less pathologically oriented care. Second, developing insight into the experience and meaning of care-giving for family members' fuelled engagement in a participatory approach that positively promoted inclusive delivery and planning of dementia care (Hansebo \& Kihlgren 2004).

Recent research from the United Kingdom has found that co-constructing family histories is innovative as it engages families directly with dementia staff in creating relatives biographies (Keady et al. 2007, Keady \& Williams 2007). This pilot found that staff engagement in this shared process resulted not only in the development of newfound knowledge but also contributed to a changing perception of roles and relationships. Such change fosters a 
motivation and an understanding of the importance of genuine participatory dementia care. At the same time such engagement promotes insight into and appreciation of, how to work with family care-givers to improve resident care outcomes. Ultimately this research has the potential to improve the aged care practice culture and combat staff experiences of frustration and overload (Venturato et al. 2006, 2007) thus making a major contribution to reducing family-staff conflict. In this changed climate, possibilities for staff recruitment and retention are improved along with levels of job satisfaction in the workplace (Moyle et al. 2003, Wenman et al. 2004).

\section{CONCLUSION}

The main contribution of this pilot study is the informing of long-term dementia care through the uncovering of new knowledge related to the use of biographical approaches in supporting the development of family-staff care partnerships. The FBW provides the means through which the views of family and the person with dementia are heard in the recalling of stories that reveal family and intergenerational history. Informed and shaped by newfound biographical knowledge, staff perceptions and attitudes are influenced and inclusive practices promoted. Ultimately, this research aims to reduce family-staff conflict, enhance the development of participatory roles and relationships and negate the effects of stress in this practice setting.

\section{RELEVANCE TO CLINICAL PRACTICE}

The study provides a practical exploration and focus group assessment of the FBW that provides: understanding of the meaning of family biography work for family and relatives in care; effective support that empowers staff to confidently relate and the means of promoting engagement in flexible and inclusive care practices that actively encourage residents' initiatives.

Moreover, this pilot study has provided direction for a larger group randomised trial to evaluate the effects of a Family Biography Program on family care-givers, residents with dementia and staff roles and relationships within the context of long-term dementia care. This research aims to promote and maintain the health of staff, family care-givers and persons with dementia by (1) creating opportunities for engagement in meaningful and satisfying care-giving roles informed and shaped by biography, (2) reducing staff, family and resident stress from role inadequacy and poor relationships and (3) improving staff attitudes towards their work and family participation. This research has the potential to improve job satisfaction and the work culture and practice environment. 
Despite this pilot research being conducted as an industry partnership project with management support, accessing staff time placed constraints on nurse participation in the study. For biographical approaches to be practically integrated into on-going dementia care in long-term settings, future designs need to be practical in terms of addressing the needs of the target group but also complementing the service philosophy, framework and workforce structure where the intervention is to be implemented (Camp 2001). This will ensure that rather than family biography work being perceived as an additional outcome-orientated task for time starved staff, it becomes an integral part of day to day dementia care (McKeown et al. 2006).

To ensure future biographical research is clinically relevant future designs need to pay closer attention to the attributes of the resident participants. Particular attention to diagnosis, level of cognitive impairment and functional abilities is important (Moyle et al. 2007) as such factors can place additional strain om family and staff care-givers and the person with dementia. To the extent that these factors are diminishing, social engagement will be impacted with consequences for family-staff attitudes, perceptions of role, relationships and satisfaction in care involvement. 


\section{Contributions}

Study design: UK

Data collection and analysis: UK, FG, CK

Manuscript central: UK, WM, MM, CK, FG

Conflict of interest:

The authors' have no known financial or personal interest in the methodology discussed in this manuscript. 


\section{REFERENCES}

Bateson P, Thorne K \& Peak J (2002): Life story work sees the person beyond the dementia. Journal of Dementia Care 10, 15-17.

Bauer M (2006): Collaboration and control: Nurses' constructions of the role of family in nursing home care. Journal of Advanced Nursing 54, 45-52.

Bern-Klug M \& Horbes-Thompson S (2008): Family members' responsibilities to nursing home residents: 'she is the only mother I got'. Journal of Gerontological Nursing 34, 43-52.

Brodaty H, Draper B \& Low L-F (2003): Nursing home staff attitudes towards residents with dementia: strain and satisfaction with work. Journal of Advanced Nursing 44, 583-590.

Camp CJ (2001): From efficacy to effectiveness to diffusion: Making the transitions in dementia intervention research. Neuropsychological Rehabilitation 11, 495-517.

Cheek J \& Ballantyne A (2001): Moving them on and in: the process of searching for and selecting an aged care facility. Qualitative Health Research 11, 221-237.

Clarke A, Hanson EJ \& Ross H (2003): Seeing the person behind the patient: Enhancing the care of older people using a biographical approach. Journal of Clinical Nursing 12, 697706.

Gaugler JE anderson KA, Zarit SH \& Pearlin LI (2004): Family involvement in nursing homes: Effects on stress and well-being. Aging and Mental Health 8, 65-75.

Gaugler JE \& Ewen HH (2005): Building relationships in residential long-term care. Journal of Gerontological Nursing 31, 19-26.

Gaugler JE, Pearlin L, Leitsch S \& Davey A (2001): Relinquishing in-home dementia care: difficulties and perceived helpfulness during the nursing home transition. American Journal of Alzheimer's Disease and Other Dementias 16, 32-42.

Haesler E, Bauer M \& Nay R (2006): Factors associated with constructive staff-family relationships in the care of older adults in the institutional setting. International Journal of Evidence-Based Healthcare 4, 288-336.

Haesler E, Bauer M \& Nay R (2007): Staff-family relationships in the care of older people: a report on a systematic review. Research in Nursing \& Health 30, 385-398.

Hansebo G \& Kihlgren M (2000): Patient life stories and current situation as told by carers in nursing home wards. Clinical Nursing Research 9, 260-279.

Hansebo G \& Kihlgren M (2004): Nursing home care: Changes after supervision. Journal of Advanced Nursing 45, 269-279.

Hardy ME \& Conway ME (1988) Role theory: perspectives for health professionals, 2nd edn. Appleton \& Lange, Norwalk, Conn.

Hegney D, Plank A, Buikstra E, Parker V \& Eley R (2005) Nurses worth listening to. University of Southern Queensland, Toowoomba.

Hepburn KW, Caron W, Luptak M, Ostwald SW, Grant L \& Keenan JM (1997): The family stories workshop: Stories for those who cannot remember. Health \& Medical Complete 37, 827832.

Hertzberg A \& Ekman S-L (2000): 'We, not them and us?' Views on the relationships and interactions between staff and relatives of older people permanently living in nursing homes. Journal of Advanced Nursing 31, 614-622.

Hertzberg A, Ekman SL \& Axelsson K (2001): Staff activities and behavior are the source of many feelings: relatives' interactions and relationships with staff in nursing homes. Journal of Clinical Nursing 10, 380-388.

Jablonski RA, Reed D \& Maas ML (2005): Care intervention for older adults with Alzheimer's Disease and related dementias. Journal of Gerontological Nursing 31, 38-48. 
Kahana E (1975): A congruence model of person-environment interaction. In Theory development in environment and ageing (P. G. Windley, T. O. Byerts \& F. G. Ernst, eds). Gerontological Society, Washington DC.

Keady J, Ashcroft-Simpson S \& Halligan K (2007): Admiral nursing and the family care of a parent with dementia: Using autobiographical narrative as grounding for negotiated clinical practice and decision making. Scandinavian Journal of Caring Sciences 21, 345353.

Keady J \& Williams S (2007): Co-constructed inquiry: A new approach to generating, disseminating and discovering knowledge in qualitative research. Quality in Ageing 8, 2736.

Kellett UM (1999a): Searching for new possibilities to care: a qualitative analysis of family caring involvement in nursing homes. Nursing Inquiry 6, 9-16.

Kellett UM (1999b): Transition in care: family carers' experience of nursing home placement. Journal of Advanced Nursing 29, 1474-1481.

Kellett UM (2000): Bound within the limits: facing constraints to family caring in nursing homes. International Journal of Nursing Practice 6, 317-323.

Kellett UM (2007): Seizing possibilities for positive family caregiving in nursing homes. Journal of Clinical Nursing 16, 1479-1487.

Luborsky, M (1994): The identification and analysis of themes and patterns. In Qualitative methods in aging research (Gubrium J.F \& Sankar A eds.). Thousand Oaks, CA, Sage, pp. 189-210.

Maas M, Reed D, Park M, Specht JP, Schutte D, Kelley LS, Swanson EA, Tripp-Reimer T \& Buckwalter KC (2004): Outcomes of family involvement in care intervention for caregivers of individuals with dementia. Nursing Research 53, 76-86.

McGilton KS \& Hall LM (2007): Supervisory support, job stress and job satisfaction among longterm care nursing staff. The Journal of Nursing Administration 37, 366-372.

McKeown J, Clarke A \& Repper J (2006): Life story work in health and social care: Systematic literature review. Journal of Advanced Nursing 55, 237-247.

Moyle W, McAllister M, Venturato L \& Adams T (2007): Quality of life: Voice of the person with dementia. Dementia: the International Journal of Social Research and Practice 6, 175191.

Moyle W, Skinner J, Roe G \& Gork C (2003): Views of job satisfaction and dissatisfaction in Australian long-term care. Journal of Clinical Nursing 12, 168-176.

Pillemer K, Suitor JJ, Henderson C, Meador R, Schultz L, Robison J \& Hegeman CR (2003): A cooperative communication intervention for nursing home staff and family members of residents. The Gerontologist 43, 96-106.

Ryan AA \& Scullion HF (2000): Family and staff perceptions of the role of families in nursing homes. Journal of Advanced Nursing 32, 626-634.

Sandberg J, Nolan MR \& Lundh U (2002): 'Entering a new world': empathic awareness as the key to positive family/staff relationships in care homes. International Journal of Nursing Studies 39, 507-515.

Sebern MD \& Whitlatch CJ (2007): Dyadic relationship scale: A measure of the impact of the provision and receipt of family care. The Gerontologist 47, 741-751.

Venturato L, Kellett U \& Windsor C (2006): Searching for value: The influence of policy and reform on nurses' sense of value in long-term aged care in Australia. International Journal of Nursing Practice 12, 326-333.

Venturato L, Kellett U \& Windsor C (2007): Nurses' experiences of practice and political reform in long-term aged care in Australia: implications for the retention of nursing personnel. Journal of Nursing Management 15, 4-11. 
Wenman K, Kihlgren M \& Fagerberg I (2004): Older people living in nursing homes or other community care facilities: registered nurses' views of their working situation and cooperation with family members. Journal of Clinical Nursing 13, 617-626.

Wilkes L, Jackson D \& Valido T (2008): Placing a relative into a nursing home: family members' experiences after the move. A review of the literature. Geriaction 26, 24-29. 